\title{
Strategic planning of a dental clinic in India
}

\author{
Shalu Jain ${ }^{1, *}$, Stuti Mohan², Pradeep Raghav ${ }^{3}$, Sumit Aggarwal ${ }^{4}$, Neelu Garg ${ }^{5}$, Shruti Choudhary ${ }^{6}$ \\ 1,2,4,5 Reader, ${ }^{3}$ Professor and Head, ${ }^{6}$ PG Student, ${ }^{1-3,6}$ Dept. of Orthodontics, ${ }^{4}$ Dept. of Prosthodontics, ${ }^{5}$ Dept. of Endodontics and \\ Conservative, ${ }^{\mathbf{1 - 4 , 6}}$ Subharti Dental College, Subhartipuram, Meerut, Uttar Pradesh, ${ }^{\mathbf{5}}$ Yamuna Institute of Dental Sciences and Research, \\ Haryana, India
}

\section{*Corresponding Author: Shalu Jain}

Email: shalu.j07@gmail.com

\begin{abstract}
After the completion of under or post graduate studies, one is always in dilemma whether to pursue career in academic field or to open up their own practice. In today's circumstances, it is well know that getting a job in dental field is very difficult so the best alternative left is to open up one's own practice. Although, it sounds to be an easy task but in reality it is not. It encompasses major steps and challenges to open up a successful dental practice in India. In literature, most of the researches are available for practice management but very few published data is present regarding how to actually start and build up a dental practice. Thus, every fresh dentist should know all the important points beforehand that have to be followed strategically step by step in opening up a dental practice.
\end{abstract}

Keywords: Dental clinic, Dental jobs, Practice management, Successful dental practice.

\section{Introduction}

In life to be successful, strategic planning plays a pivotal role in accomplishing both personal and professional goals. Like any other profession in the world, be it opening a small food joint to opening a fully fledged industry, planning and designing the establishment is always a game changer and we dentists are no exception. As we know that in today's scenario there are no adequate jobs for dentists in India, ${ }^{1}$ so the one of the best option is to open up one's own dental practice. Planning of a dental clinic demands a high level of commitment, business acumen, marketing knowledge, industry awareness and above all awareness on various aspects of the practice. In literature, all the information pertaining to this topic is mostly available for western or European countries which cannot be applied to Indian domestic conditions. Secondly, there is much of research on practice management but nothing much about to how to establish one's practice.

\section{Discussion}

For establishing a successful dental practice in India, one needs to accomplish and fulfil various goals which are:

A. Choosing a right site of practice,

B. Building a good and appropriate infrastructure,

C. Getting approval from the concerned authorities,

D. Figuring out the current marketing strategy,

E. Financial management,

F. Protection of doctors,

G. Hiring right people and

H. Maintain and assess

All the above mentioned steps will be dealt in detail below:

A. Choosing a right site of practice: This can be done by choosing a right property with a good location, be it either in a small city or a big city. Finding a right property is determined by 2 inter-related factors firstly where a person want to live \& settle and secondly scope for practice in that location. There should always be a balance between good professional lifestyle and desired life-style.
Property can be of two types residential or commercial. Both of these two have some advantages and disadvantages associated with them. For residential property, the obvious advantage is that one is privileged with a space to open up their dental practice in own residential property but in that also dentist have to pay the electricity rent because according to law, although, doctors are permitted to use $30 \%$ FAR of their premises for their professional activities. However a separate commercial electricity meter is required, so one has to pay the rent for it because eventually the property owner has to show that expense while filling for the income tax return.

Another, advantage associated with it is one can save the cost for wear and tear of vehicle and secondly your commute time is saved. As we know that time is money and in today's scenario, commuting takes more time due to heavy traffic jams than any kind of dental procedure.

On the other hand in commercial property, the advantages associated with it is that one can expect more number of patient footfalls and is more exposed to the public but the disadvantages are that the commercial property is generally more expensive, may not be available in terms of ready to move in and of adequate size. Along with this one has to pay added cost of vehicle wear $n$ tear and fuel cost while commuting. So a tip here is to try and find a space that fits into the budget but never go for the cheapest place if the location is not too good.

Once a right property is selected according to personal goals, the second important step is finding a good location. There are 6 important factors and its associated demographics that one should check for before selecting any location: ${ }^{2}$

1. Commute time: The location should be such that you spend minimum time in commute which will give you more time for your patients and yourself.

2. Locale: Make sure the clinic is set up in an area that will have a decent reputation among the target patients. The Consultation fees can be a good metric to determine the apt 
area for the dental practice. For example, setting up a posh clinic in substandard area will keep the customers away thinking that services offered are too expensive. Whereas, setting up a substandard clinic in a way too posh area can make the patients gets disinterested soon.

3. Neighbourhood: Adjacent and nearby shops and offices play a very important role in building an early impression of a dental clinic. Because a doctor's clinic is expected to be an absolutely clean place which stands for hygiene and good health and one should make sure that the area surrounding the clinic also reflects this, with minimal pollution (noise, air or water) or litter in the neighbourhood.

4. Proximity to Hospitals: Having hospitals in the immediate vicinity could turn out to be a boon. Because of two factors, firstly one can get associated with it and secondly, any emergency situation can be handled without delay.

5. Visibility: it is very important to be easily visible to passerby because then only he or she can recall even after going home. It's one's choice and depending on individual budget a dentist can select a prime location or a basement. The point is that the clinic should be visible through display or sign board. Thus, check the visibility for displaying a banner or required signage. Although, a space with prime visibility might cost a little more than a clinic in a basement or perhaps in a small by-lane, but, think of it as an investment in marketing the clinic which will definitely give long term results.

6. Accessibility: The location of the clinic should be very accessible with lots of commute options from across the city / town. As old patient prefer to get dropped off just outside the clinic.

B. Building a good and appropriate infrastructure: The status of the building i.e. both its exterior and interior plays an important role.

1) Exterior: It is the first thing that strikes patients and makes an early impression for the consultation. So, firstly, one should make sure that the exterior of the building is not too shabby. Secondly, there should be ample parking area for the visitors as today finding a parking space is a very tedious process. Also, if possible, employment of security personnel who can also assist patients with finding parking spots can give an edge in comparison to other clinics.

2) Interiors: To provide a great patient experience, the interiors of clinic are very important since the time a patient enters in your clinic till the time he is called for the procedure. For passing their time when they are waiting and to keep them comfortable one can provide various amenities like air-conditioning and television.

\section{C) Getting approval from the concerned authorities}

These include:

1. Clinic Establishment Act Registration

2. Bio-Waste Disposal Registration

3. Fire Registration

As per latest High Court order all doctors and clinic/ hospital owners are required to get their centres registered with $\mathrm{CMO}$ and if already registered then renew it before 30th April 2015. It covers all doctors' single practitioners as well. This registration can be done via clinical establishment act and the details are available on internet as well.

The main objective of this act is to make available a database of clinical establishments which are authorized to function and also to improve public health quality by eliminating quacks.

Registration can be of two types:

a. Provisional registration:

i. No inspection or enquiry is done for provisional registration for a period of ten days from the date of receipt of application.

ii. Validity of provisional registration remains till the last day of the twelfth month.

iii. Renewal of provisional registration should be made with the authority within thirty days before the expiry of the validity of the certificate of provisional registration.

b. Permanent registration

i. Validity of permanent registration is valid for a period of five years from the date of issue of the certificate of registration and such registration is renewable.

ii. Renewal of permanent registration should be made six months before the expiry of validity of the certificate of permanent registration and in case the application is not submitted within the stipulated time, then renewal would be done with the impounding enhanced fees and penalty.

For any type of registration, a dentist should register at individual state CMO office or download forms from their respective website.

D) Figuring out the current marketing strategy: A very important step as without publicity a dentist cannot expect new patient footfall easily. Marketing strategy involves publicity through advertisements in newspapers, radio, social media platforms such as Facebook, Instagram or WhatsApp groups etc. One can also create own website which will ease tasks such as taking appointments, making payments and other options.

E) Financial management: One has to get acquainted with all the essential and non essential costs of running a dental clinic which will help in eliminating the surprise factor and will prepare for any financial bottlenecks.

1. Property costs for dental clinics

i. Since rental costs keep changing from time to time, it is important to know general trends \& rate brackets of the choosen property, for efficient planning at the particular time when one is ready to open up a dental clinic. The cost can be checked out with property dealer or can visit website for the commercial property rates at Magicbricks and Housing, among other websites. ${ }^{3}$

2. The costs of running a dental clinic include -2 groups:

A. Dental treatment costs:

i. On-time costs for dental chair and hard equipment. Other on-time costs for X-Ray sensors, dental drills, and basic hand instruments.

B. Running costs of a dental clinic: 
i. Rent and maintenance costs

ii. Electricity, water, phone \& internet bills

iii. White goods, such as computers, air conditioners, refrigerators

iv. Staff, namely the receptionist, paramedical assistants $\&$ associate doctors.

v. Marketing costs, like signage and advertising.

For efficient financial management, one must have a separate current bank account in the name of the dental clinic. It is also mandatory for accounting records for practice. If the annual receipts are more than Rs 1.5 lakhs in each of the past 3 years, one should keep some form of financial books such as -Cash book, Journal, Ledger, Copies of bills and Original bills of expenditure.

There are some additional requirements for doctors i.e. Daily cash register with details of patients, services rendered, fees received and date of receipt and Details of stock of drugs, medicines, and other consumables used. Also, one should Consult CA for timely advice and for filling IT return. ${ }^{4}$

F) Protection of doctors and patients: All dentists are expected to be vaccinated against all immunizable infectious diseases amongst which hepatitis B is a major concern today. Other conditions such as Influenza should be taken care of on an annual basis.

If the clinicians live in endemic areas of Cholera, or travel frequently to endemic areas of Cholera, the clinicians should be vaccinated against Cholera also. ${ }^{5}$

For protection of patients dental Indemnity in India is a new chapter. It means a security or protection against a loss or other financial burden. Rural as well as urban society, are only aware about the treatment options but have very limited information about the situations which come under "DENTAL NEGLIGENCE". To save the interests of both patients as well making dentist more accountable while delivering their services dental indeminity overcomes the missing link between the two situations mentioned above. There are various indemnity plans available today. This dental plan pays the dental office on a traditional fee for service basis. A monthly premium is paid by the client and/or the employer to an insurance company which then reimburses the dentist for the services rendered. A insurance company usually pays between 50 to $80 \%$ of the dental office (dentist) fees for a covered procedures; the remaining 20 to $50 \%$ is paid by the client. Indeminity plans also can limit the amount of services covered within the given year and pay the dentist based on a variety of fee schedule.

G) Hiring right people: Managing the entire clinic all by your self is a daunting task. Thus, hiring people skilled in medical treatments and clinic management will help focus on the core i.e. treating patients. Make sure to hire people having proper clinical knowledge and practical experience so as to reduce stress and time in training ${ }^{7}$.

H) Maintain and assess

This could be accomplished through:

1. Regular Quality Checks on Dental Equipments.

2. Maintaining Accounts and Assessing profits.
3. Checking Expiry Dates of consumable Materials.

4. Providing Upgraded Training Sessions to Staff. ${ }^{7}$

\section{Conclusion}

Starting your own dental practice can be a very exciting endeavor, which requires strategic planning, designing, organization skills and attention to all minute details.

\section{Source of Support: Nil}

\section{Conflict of Interest: Nil}

\section{References}

1. Y Sankalp and R Gautam. The current status of dental graduated in India. Pan Afr Med J 2016;23:22.

2. 2. https://doctors.practo.com/complete-guide-choosing-cliniclocation

3. https://doctors.practo.com/cost-of-setting-up-running-dentalclinic-india

4. https://cleartax.in/s/6-forms-of-taxable-income-for-doctors

5. Infection Control \& Occupational Safety Recommendations for Oral Health Professionals in India 2007: a book by Dr. Anil Kohli and Dr. Raghunath Puttaiah

6. Mahajan A, Bedi R, Mahajan P (2014) Dental Indemnity in India-A Missing Link. Dentistry 4: 253

7. Beginner's Guide to Establish a Dental Clinic in India (Prep ladder)

How to cite this article: Jain S, Mohan S, Raghav P, Aggarwal S, Garg N, Choudhary S. Strategic planning of a dental clinic in India. Int Dent J Student's Res. 2018;6(4):74-76. 